Article

\title{
Chain Entanglement of 2-Ethylhexyl Hydrogen-2-Ethylhexylphosphonate into Methacrylate-Grafted Nonwoven Fabrics for Applications in Separation and Recovery of Dy (III) and Nd (III) from Aqueous Solution
}

\author{
Hiroyuki Hoshina *, Jinhua Chen *(D, Haruyo Amada and Noriaki Seko \\ Department of Advanced Functional Materials Research, Takasaki Advanced Radiation Research Institute, \\ Quantum Beam Science Research Directorate, National Institutes for Quantum and Radiological Science and \\ Technology, 1233 Watanuki-machi, Takasaki, Gunma 370-1292, Japan; amada.haruyo@qst.go.jp (H.A.); \\ seko.noriaki@qst.go.jp (N.S.) \\ * Correspondence: hoshina.hiroyuki@qst.go.jp (H.H.); chen.jinhua@qst.go.jp (J.C.); Tel.: +81-27-346-9125 (J.C.)
}

Received: 27 October 2020; Accepted: 9 November 2020; Published: 11 November 2020

\begin{abstract}
A nonwoven fabric adsorbent loaded with 2-ethylhexyl hydrogen-2-ethylhexylphosphonate (EHEP) was developed for the separation and recovery of dysprosium (Dy) and neodymium (Nd) from an aqueous solution. The adsorbent was prepared by the radiation-induced graft polymerization of a methacrylate monomer with a long alkyl chain onto a nonwoven fabric and the subsequent loading of EHEP by hydrophobic interaction and chain entanglement between the alkyl chains. The adsorbent was evaluated by batch and column tests with a Dy (III) and Nd (III) aqueous solution. In the batch tests, the adsorbent showed high Dy (III) adsorptivity close to $25.0 \mathrm{mg} / \mathrm{g}$ but low Nd (III) adsorptivity below $1.0 \mathrm{mg} / \mathrm{g}$, indicating that the adsorbent had high selective adsorption. In particular, the octadecyl methacrylate (OMA)-adsorbent showed adsorption stability in repeated tests. In the column tests, the OMA-adsorbent was also stable and showed high Dy (III) adsorptivity and high selectivity in repeated adsorption-elution circle tests. This result suggested that the OMA-adsorbent may be a promising adsorbent for the separation and recovery of Dy (III) and Nd (III) ions.
\end{abstract}

Keywords: selective adsorption; dysprosium; neodymium; fabric adsorbent; radiation; graft polymerization

\section{Introduction}

Rare earths including scandium, yttrium, and 15 lanthanoid elements, have recently become indispensable materials for the high-tech industry. Due to the uneven distribution of rare-earth sources in the world, almost all rare earths are supplied by limited countries [1]. Therefore, it is necessary to recycle used rare earths to ensure a stable supply of these materials in many countries [2-7]. Among the rare earths, dysprosium (Dy) and neodymium (Nd) are listed as "critical materials" by the United States due to supply issues and their importance to electronics and electrical technology [8,9]. For example, neodymium and dysprosium are key components of permanent magnets, such as NdFeB magnets. The demand for the separation and recovery of dysprosium and neodymium from used permanent magnets and scraps generated during manufacturing is increasing [10-20].

The technology for the separation and recovery of dysprosium and neodymium from used permanent magnets has been extensively studied [21,22]. The most common method of recovering dysprosium and neodymium from waste materials involves leaching them in an acid solution and purifying the leached ions by solvent extraction [11-13,23]. Organophosphorus compounds such as 
2-ethylhexyl hydrogen-2-ethylhexylphosphonate and di(2-ethylhexyl)phosphoric acid, carboxylic acid such as neodecanoic acid and naphthenic acid, and methyltrioctylamine chloride are usually used as extractants for rare-earth ions due to their good separation and recovery performance [22-26]. However, solvent extraction requires a large number of separation steps, a long processing time, and a large space for all necessary equipment. On the other hand, other methods such as chemical precipitation and ionic liquids extraction are also used for the separation and recovery of rare earths. Although the chemical precipitation process is simple and low in cost, the purity and recovery ratio of the resulting product are usually low, while the ionic liquid extraction cost is high for actual application [21]. Currently, the effective separation and recovery of rare earths from an aqueous solution requires relatively simple processes [27,28]. Adsorption techniques using adsorbents, such as inorganic particles, ion-exchange resins, and polymer ligands, are attractive for the separation and recovery of rare-earth ions [29-36]. This is because the adsorption process does not require much energy and water and can be easily operated anywhere by batch or column methods [37].

Inorganic particles, such as clay minerals, activated carbon, and magnetite nanoparticles, are highly suitable for removing heavy metals from water and wastewater. In many cases, these inorganic materials show high adsorption but low selectivity [37-39]. On the other hand, adsorbents with special ligands or chelating functional groups can be designed to selectively separate and recover target metal ions in water. These adsorbents, including ion-exchange resins and polymer ligands, can be prepared by introducing functional groups onto polymer materials by the radiation-induced graft polymerization method. This method can introduce new functional properties while maintaining the properties of the trunk polymers [40-48]. Various vinyl monomers have been radiation-grafted onto trunk polymers, such as polyethylene [41,42], polypropylene [43,44], fluoropolymers [45], and cellulose [46,47]. Furthermore, graft polymerization can be applied to various types of materials, such as films [45], fabrics [30,45-47], fibers [46], and particles [48]. Various adsorbents have been developed using this technology for the recovery and removal of metal ions from environmental water and industrial wastewater [46-51]. In the design of these adsorbents, it is important to select the most suitable functional groups based on the metal ion that needs to be adsorbed.

We noticed that 2-ethylhexyl hydrogen-2-ethylhexylphosphonate (EHEP), used as an extractant in the solvent extraction process, has two alkyl chains on each molecule $[10,24,52]$. In this study, we attempted to load EHEP onto polyethylene-coated polypropylene (PE/PP) nonwoven fabrics to develop a novel adsorbent for rare-earth ions. For this purpose, we grafted a polymerized methacrylate monomer with a long alkyl chain onto the fabrics. The EHEP was then loaded onto the grafted fabrics by hydrophobic interaction and chain entanglement between the alkyl chains. Here, since the EHEP is only physically bonded on the fabrics by hydrophobic interaction and chain entanglement, the loss of EHEP is a concern in practical applications. Therefore, the stability of EHEP-loaded adsorbents needs to be confirmed for practical use.

Four methacrylate monomers with different alkyl chain lengths-butyl methacrylate (BMA), hexyl methacrylate (HMA), dodecyl methacrylate (DMA), octadecyl methacrylate (OMA) - were radiation-grafted onto the $\mathrm{PE} / \mathrm{PP}$ nonwoven fabrics in this study. The grafted fabrics were then loaded with EHEP to prepare the adsorbents. The adsorbents were tested in batch and column modes using Dy (III) and Nd (III) ion solutions [18]. The effects of the alkyl chain length of the monomers on the stability and adsorption performance of the EHEP-loaded absorbents were studied and evaluated.

\section{Experimental}

\subsection{Materials}

The trunk material used for graft polymerization was a nonwoven fabric composed of polyethylene-coated polypropylene (PE/PP) fibers, provided by Kurashiki Textile Manufacturing Co., Ltd., Kurashiki, Japan. The PE on the fiber surface is easy to be radiation-grafted, and the PP core makes the fiber mechanically stronger. Furthermore, the PE/PP nonwoven fabric is relatively cheap 
among artificial fabrics and has a large specific surface. The four methacrylate monomers-butyl methacrylate (BMA), hexyl methacrylate (HMA), dodecyl methacrylate (DMA), and octadecyl methacrylate (OMA) - are of chemical reagent grade and were purchased from Fujifilm Wako Pure Chemical Corporation, Tokyo, Japan. 2-Ethylhexyl hydrogen-2-ethylhexylphosphonate (EHEP) was provided by Daihachi Chemical Industry Co., Ltd., Tokyo, Japan. The other reagents, such as Tween 20 surfactant, methanol, ammonia water, $\mathrm{HCl}$ solution, $\mathrm{Dy}$ (III) $\left(\mathrm{Dy}_{2} \mathrm{O}_{3}\right.$ in $5 \mathrm{wt}$. $\left.\% \mathrm{HNO}_{3}\right)$ standard solution, and $\mathrm{Nd}$ (III) $\left(\mathrm{Nd}_{2} \mathrm{O}_{3}\right.$ in $\left.5 \mathrm{wt} . \% \mathrm{HNO}_{3}\right)$ solution, were purchased from Kanto Chemical Co., Inc., Tokyo, Japan. All chemicals were used without further purification. In this study, the deionized Mili-Q water with a high resistivity of $18 \mathrm{M} \Omega \mathrm{cm}$ was used.

\subsection{Graft Polymerization of Methacrylate Monomers}

Figure 1 shows the process of preparing the fabric adsorbents. Graft polymerization was performed using a preirradiation method. In this study, either PE nonwoven fabric or PP nonwoven fabric could be used as trunk polymers. However, the mechanical strength of common PE nonwoven fabric is significantly lower than that of PP nonwoven fabric, while the PP nonwoven fabric deteriorates faster than PE nonwoven fabric. Therefore, we chose the PE-coated PP nonwoven fabric as the polymer trunk for radiation grafting. The PE/PP nonwoven fabric with a size of $5 \mathrm{~cm} \times 8 \mathrm{~cm}$ was placed in a polyethylene bag, purged with nitrogen gas to create an oxygen-free environment, and electron beam preirradiated at $-80^{\circ} \mathrm{C}$ (dry ice) with a beam energy of $2 \mathrm{MeV}$ at a current of $3 \mathrm{~mA}$ to generate radicals on the fabric. The preirradiated fabric was removed and filled into a glass ampoule, which was evacuated and filled with a nitrogen-bubbled monomer solution to immerse the fabric completely. The ampoule was placed in a temperature-controlled oven. Under these conditions, the radicals initiated graft polymerization. The monomer structures and grafting conditions are shown in Table 1. After graft polymerization, the fabric was washed with methanol to remove residual monomers and homopolymers and dried in an oven at $60^{\circ} \mathrm{C}$ for more than $24 \mathrm{~h}$.

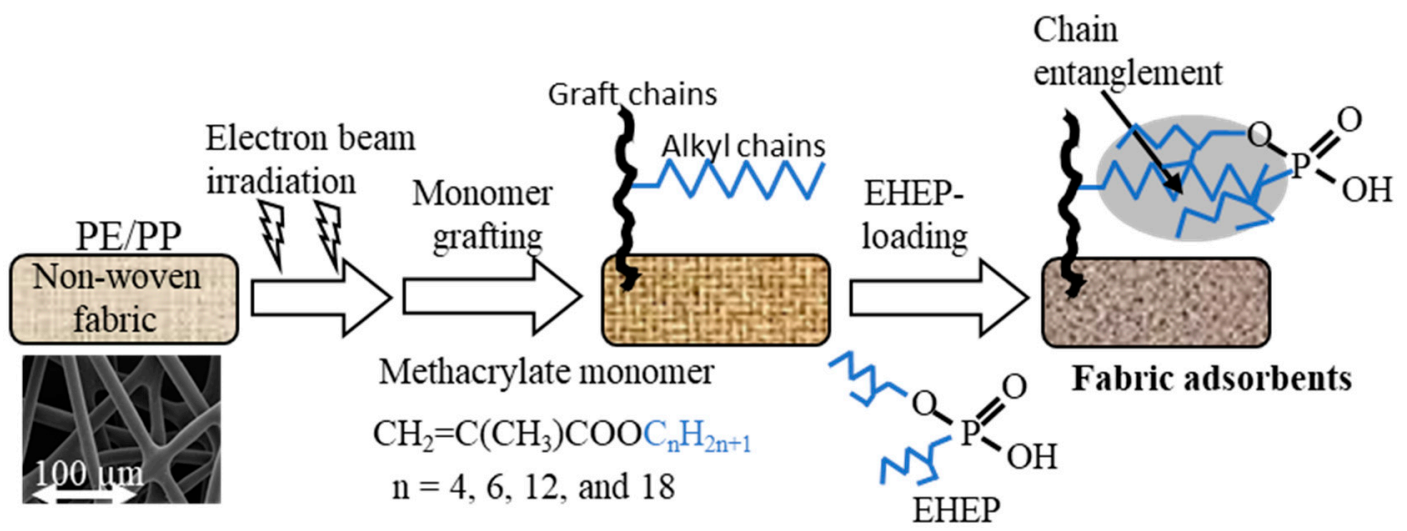

Figure 1. Preparation of the fabric adsorbents by graft polymerization of methacrylate monomers and the subsequent 2-ethylhexyl hydrogen-2-ethylhexylphosphonate (EHEP) loading.

The degree of grafting and the density of alkyl chains of the grafted fabrics were calculated using the following equations.

$$
\begin{gathered}
\text { Degree of grafting }(\%)=\left(\mathrm{W}_{\mathrm{g}}-\mathrm{W}_{0}\right) / \mathrm{W}_{0} \times 100 \\
\text { Density of alkyl chains }(\mathrm{mmol} / \mathrm{g})=1000 \times\left(\mathrm{W}_{\mathrm{g}}-\mathrm{W}_{0}\right) / \mathrm{M} / \mathrm{W}_{\mathrm{g}}
\end{gathered}
$$

where $\mathrm{W}_{0}$ and $\mathrm{W}_{\mathrm{g}}$ are the dry weights $(\mathrm{mg})$ of the fabrics before and after graft polymerization, and $\mathrm{M}$ is the molecular weight of the monomers as shown in Table 1. 
Table 1. Methacrylate monomers and grafting conditions used in this study.

\begin{tabular}{|c|c|c|c|c|c|}
\hline \multirow[b]{2}{*}{ Name } & \multirow[b]{2}{*}{ Molecular Structures } & \multirow[b]{2}{*}{$\mathbf{M} *$} & \multicolumn{3}{|c|}{ Grafting Conditions ** } \\
\hline & & & $\begin{array}{c}\text { Dose }{ }^{* * *} \\
(\mathrm{kGy})\end{array}$ & $\begin{array}{l}\text { Temp. } \\
\left({ }^{\circ} \mathrm{C}\right)\end{array}$ & $\begin{array}{l}\text { Time } \\
\text { (min) }\end{array}$ \\
\hline Butyl methacrylate (BMA) & $\mathrm{CH}_{2}=\mathrm{CCH}_{3} \mathrm{COOC}_{4} \mathrm{H}_{9}$ & 142 & 10 & 40 & 15 \\
\hline Hexyl methacrylate (HMA) & $\mathrm{CH}_{2}=\mathrm{CCH}_{3} \mathrm{COOC}_{6} \mathrm{H}_{13}$ & 170 & 10 & 60 & 30 \\
\hline Dodecyl methacrylate (DMA) & $\mathrm{CH}_{2}=\mathrm{CCH}_{3} \mathrm{COOC}_{12} \mathrm{H}_{25}$ & 254 & 300 & 60 & 180 \\
\hline Octadecyl methacrylate (OMA) & $\mathrm{CH}_{2}=\mathrm{CCH}_{3} \mathrm{COOC}_{18} \mathrm{H}_{37}$ & 338 & 100 & 60 & 120 \\
\hline
\end{tabular}

\subsection{Loading of EHEP onto the Grafted Fabrics}

A $50 \mathrm{wt} . \%$ EHEP solution of ethanol was uniformly dropped onto the grafted fabric for EHEP loading. The EHEP-loaded fabric was dried in a vacuum oven at $40^{\circ} \mathrm{C}$ to remove the ethanol solvent. EHEP loading of the resulting fabric adsorbent was calculated by the following equation.

$$
\text { EHEP loading }(\mathrm{mmol} / \mathrm{g})=1000 \times\left(\mathrm{W}_{\mathrm{a}}-\mathrm{W}_{\mathrm{g}}\right) / 306 / \mathrm{W}_{\mathrm{a}}
$$

where $W_{a}$ is the dry weights $(\mathrm{mg})$ of EHEP-loaded fabric, and 306 is the molecular weight of EHEP. The prepared fabric adsorbents with different monomers were named BMA-, HMA-, DMA-, and OMA-adsorbent, respectively.

\subsection{Characterization}

Fourier transform infrared (FTIR) spectroscopic analysis was performed with an FTIR spectrophotometer in the attenuated total reflectance (ATR) mode (Spectrum One, PerkinElmer, Inc., Tokyo, Japan). The scanning range and resolution were $500-2500 \mathrm{~cm}^{-1}$ and $1 \mathrm{~cm}^{-1}$, respectively.

The hydrophobicity of the grafted fabric was examined by measuring the contact angle with a contact angle meter (CA-X, Kyowa Interface Science Co., Ltd., Tokyo, Japan).

\subsection{Batch Adsorption Tests}

The prepared fabric adsorbent was evaluated by batch adsorption tests. The test solution contained $100 \mathrm{ppm}$ Dy (III) and $100 \mathrm{ppm} \mathrm{Nd} \mathrm{(III).} \mathrm{The} \mathrm{pH}$ of the test solution was adjusted to 2.0 by ammonia water. The fabric adsorbent with a size of $2 \mathrm{~cm} \times 2 \mathrm{~cm}$ was immersed in $50 \mathrm{~mL}$ of test solution in a glass bottle. The bottle was placed on a shaker and shaken at a rate of $150 \mathrm{rpm}$ at $25^{\circ} \mathrm{C}$ for $3.0 \mathrm{~h}$. After the adsorption test, the adsorbent was washed with deionized water to remove the unadsorbed ions on them.

To elute the adsorbed ions, the fabric adsorbent was immersed in $50 \mathrm{~mL}$ of $1.0 \mathrm{M} \mathrm{HCl}$ solution in a glass bottle, and the bottle was shaken at a rate of $150 \mathrm{rpm}$ at $25^{\circ} \mathrm{C}$ for $1.0 \mathrm{~h}$. After elution, the fabric adsorbent was washed with deionized water and adsorption was repeated under the same conditions as the first adsorption test.

The ion concentrations in the adsorption and elution solutions were analyzed before and after each test with an inductively coupled plasma optical emission spectrometer (ICP-OES, Optima 8300, PerkinElmer, Inc., Tokyo, Japan). The adsorptivity ( $\mathrm{mg} / \mathrm{g}$ ) of the fabric adsorbent was calculated as follows.

$$
\text { Adsorptivity }(\mathrm{mg} / \mathrm{g})=1000 \times\left(\mathrm{C}_{0}-\mathrm{C}_{\mathrm{i}}\right) \times \mathrm{V} / \mathrm{W}_{\mathrm{a}}
$$

where $C_{0}(\mathrm{mg} / \mathrm{mL})$ and $C_{i}(\mathrm{mg} / \mathrm{mL})$ are the metal ion concentrations in the solution before and after the adsorption, respectively, and $\mathrm{V}(\mathrm{mL})$ is the volume of the solution. 


\subsection{Column Adsorption Tests}

For the column adsorption tests, the fabric adsorbent with a diameter of $7.0 \mathrm{~mm}$ was packed into a column with an inner diameter of $7.0 \mathrm{~mm}$. The volume of the adsorbent packed in the column was $0.2 \mathrm{~mL}$. The test solution (100 ppm Dy (III) and $100 \mathrm{ppm} \mathrm{Nd} \mathrm{(III),} \mathrm{pH}$ 2) was passed through the column at a space velocity (SV) of $100 \mathrm{~h}^{-1}$ at $25^{\circ} \mathrm{C}$. The SV is calculated by dividing the solution flow rate $(\mathrm{mL} / \mathrm{h})$ by the volume of adsorbent in the column (fixed at $0.2 \mathrm{~mL}$ in this study). A fraction collector was used to continuously collect the effluent from the column, and the ion concentrations were detected by ICP-OES. By plotting the relationship between $\mathrm{C}_{\mathrm{i}}$ and bed volume (BV), the ion concentration curve of the effluent was obtained. Here, $C_{i}$ is the ion concentration of the effluent at $B V$, and $B V$ is calculated by dividing the total effluent volume from the column by the adsorbent volume $(0.2 \mathrm{~mL})$.

The adsorptivity ( $\mathrm{mg} / \mathrm{g}$ ) of the adsorbent packed in the column was calculated by the following equation

$$
\text { Adsorptivity }(\mathrm{mg} / \mathrm{g})=1000 \times \sum\left(\mathrm{C}_{0}-\mathrm{C}_{\mathrm{i}}\right) \Delta \mathrm{V}_{\mathrm{i}} / \mathrm{W}_{\mathrm{a}}
$$

where $\Delta \mathrm{V}_{\mathrm{i}}(\mathrm{mL})$ and $\mathrm{C}_{\mathrm{i}}(\mathrm{mg} / \mathrm{mL})$ are the volume and concentration of each collected effluent during the adsorption, respectively.

After the adsorption test, the adsorbent was thoroughly washed by passing deionized water through the column. Then, $1.0 \mathrm{M} \mathrm{HCl}$ solution of the eluent was passed through the column with a space velocity of $100 \mathrm{~h}^{-1}$ at $25^{\circ} \mathrm{C}$ until no metal ions were detected in the effluent. The eluted amount $(\mathrm{mg} / \mathrm{g})$ and recovery ratio were calculated by the following equations.

$$
\begin{gathered}
\text { Eluted amount }(\mathrm{mg} / \mathrm{g})=1000 \times \sum \mathrm{C}_{\mathrm{i}} \Delta \mathrm{V}_{\mathrm{i}} / \mathrm{W}_{\mathrm{a}} \\
\text { Recovery ratio }(\%)=\text { Eluted amount } / \text { Adsorptivity } \times 100
\end{gathered}
$$

where $\Delta \mathrm{V}_{\mathrm{i}}(\mathrm{mL})$ and $\mathrm{C}_{\mathrm{i}}(\mathrm{mg} / \mathrm{mL})$ are the volume and concentration of each collected effluent during the elution, respectively.

After the elution test, the adsorbent in the column was thoroughly washed with deionized water and used for the adsorption test again to evaluate its stability.

\section{Results and Discussion}

\subsection{Synthesis of EHEP-Loaded Adsorbent}

The adsorbent was prepared by the radiation-induced graft polymerization of methacrylate with a long alkyl chain onto PE/PP nonwoven fabric and the subsequent loading of EHEP by hydrophobic interaction and chain entanglement between the alkyl chains. Here, the EHEP organophosphorus compound has a special affinity for Dy (III) ions. The grafting results and the density of EHEP loading are summarized in Table 2.

Table 2. Degree of grafting and alkyl group density of the grafted fabrics, and the EHEP loading of the corresponding adsorbents.

\begin{tabular}{lccc}
\hline \multicolumn{1}{c}{ Grafted Monomers } & Degree of Grafting (\%) & $\begin{array}{c}\text { Alkyl Group } \\
\text { Density * (mmol/g) }\end{array}$ & $\begin{array}{c}\text { EHEP Loading ** } \\
\text { (mmol/g) }\end{array}$ \\
\hline Butyl methacrylate (BMA) & 51 & 2.39 & 1.24 \\
\hline Hexyl methacrylate (HMA) & 62 & 2.24 & 1.26 \\
\hline Dodecyl methacrylate (DMA) & 102 & 1.99 & 1.24 \\
\hline Octadecyl methacrylate (OMA) & 219 & 2.03 & 1.22 \\
\hline $\begin{array}{l}* \\
\text { Alkyl group density of the monomer-grafted fabric was calculated using Equation (2); ** EHEP loading was }\end{array}$
\end{tabular}


As shown in Table 2, four monomers with different alkyl chain lengths-BMA, HMA, DMA, and OMA-were radiation-grafted onto the fabrics. For comparison, the alkyl chain density in the grafted fabric was adjusted to be close to $2.0 \mathrm{mmol} / \mathrm{g}$. For this reason, the degree of grafting was significantly different for each monomer and increased in proportion to the molecular weight of the grafted monomer. For example, to obtain a similar alkyl chain density of $2.0 \mathrm{mmol} / \mathrm{g}$, the degree of grafting for the BMA is $51 \%$, while it is $219 \%$ for the OMA. The latter is approximately four times higher than that of the former.

To obtain similar alkyl chain densities of the grafted fabrics, BMA grafting was carried out by immersing the $10 \mathrm{kGy}$ preirradiated fabric into a $5.0 \mathrm{wt} . \%$ BMA emulsion at $40{ }^{\circ} \mathrm{C}$ for $15 \mathrm{~min}$, while for HMA grafting, a higher temperature of $60^{\circ} \mathrm{C}$ and longer grafting time of $30 \mathrm{~min}$ were needed. We also carried out BMA grafting at $60^{\circ} \mathrm{C}$. However, the grafting rate was too fast to control the graft yielding. For monomers with longer alkyl chains, preirradiation doses higher than $100 \mathrm{kGy}$ were used to generate more radicals in the fabrics. This is because the steric hindrance effects of the monomers inhibited the graft polymerization from reaching a high degree of grafting. Furthermore, a mixture solvent of methanol and water in the ratio of 1:1 was used for OMA grafting. Here, the addition of methanol to the monomer solution increased the affinity between the fabric and the monomer, thereby enhancing the radiation grafting [53].

The loading of EHEP onto the grafted fabric was achieved by dropping the EHEP solution of ethanol onto the grafted fabric to reach a loading density of approximately $1.2 \mathrm{mmol} / \mathrm{g}$. After removing ethanol by evaporation, the adsorbent was obtained.

\subsection{Materials Characterization}

The FTIR results shown in Figure 2 confirmed that the BMA, HMA, DMA, and OMA monomers were graft polymerized onto the PE/PP nonwoven fabrics and EHEP was loaded onto the OMA-grafted fabric. The peaks of the PE/PP nonwoven fabric only appeared at 1472, 1462, 1375, 731, and $718 \mathrm{~cm}^{-1}$, corresponding to the characteristic absorptions of PE [54], indicating that the PP fiber was completely coated by PE. After grafting, new peaks at 1730 and $1155 \mathrm{~cm}^{-1}$, attributed to the $\mathrm{C}=\mathrm{O}$ and $\mathrm{C}-\mathrm{O}$ stretching of methacrylate, respectively, were observed (Figure $2 b-e)[55,56]$. After loading EHEP onto the OMA-grafted fabric, new peaks at $1250(\mathrm{P}-\mathrm{O}-\mathrm{C}), 1050(\mathrm{P}-\mathrm{O}-\mathrm{C})$, and $980(\mathrm{P}=\mathrm{O}) \mathrm{cm}^{-1}$ were observed, as shown in Figure $2 \mathrm{f}$ [25]. These results indicated that the methacrylate monomers were grafted onto the fabrics and EHEP was loaded onto the OMA-grafted fabric.

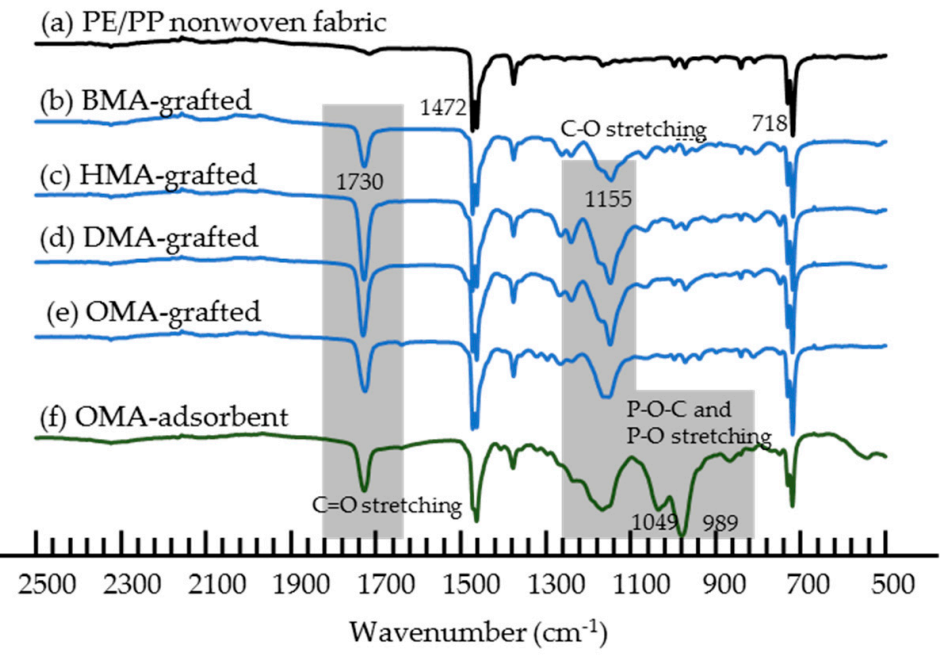

Figure 2. FTIR spectra of (a) PE/PP nonwoven fabric, (b) BMA-grafted PE/PP nonwoven fabric, (c) HMA-grafted PE/PP nonwoven fabric, (d) DMA-grafted PE/PP nonwoven fabric, (e) OMA-grafted $\mathrm{PE} / \mathrm{PP}$ nonwoven fabric, and (f) OMA-adsorbent prepared by loading of EHEP onto the OMA-grafted PE/PP nonwoven fabric. 
The surface properties of the BMA-, HMA-, DMA-, and OMA-grafted fabrics were evaluated by a contact angle meter. A high contact angle indicates the high hydrophobicity of the sample. Pictures of water droplets on the surface with the smallest and largest contact angles are shown in Figure 3a, b, respectively. The contact angle of the BMA-grafted fabric was $97^{\circ}$ (Figure 3a), while that of the OMA-grafted fabric was $112^{\circ}$ (Figure $3 b$ ). For comparison, the contact angles of the grafted fabrics are summarized in Figure 3c. The contact angle increased with the increase of the alkyl chain length of the grafted monomers. The OMA-grafted fabric had the highest hydrophobicity due to the longest alkyl chains of the grafted monomers as well as the highest degree of grafting (see Table 2). It was expected that the grafted fabric with high hydrophobicity was more conducive to the physical bonding of the alkyl chain of EAEH for loading.

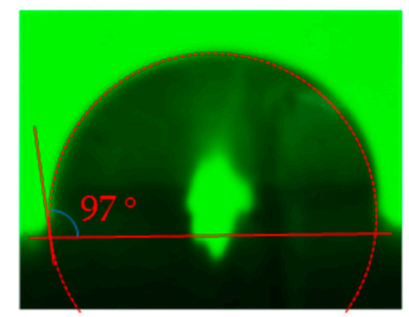

(a) BMA-adsorbent

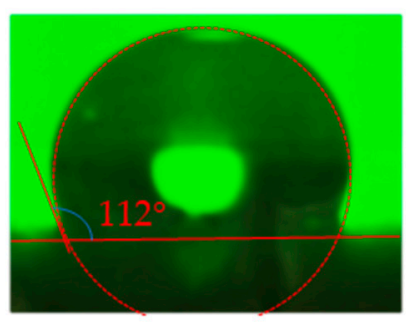

(b) OMA-adsorbent

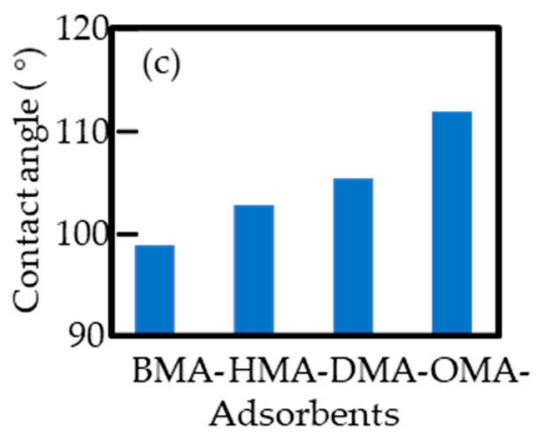

Figure 3. Water droplets on the BMA-adsorbent (a) and OMA-adsorbent (b). Contact angle of the water droplets on the four fabric adsorbents (c).

\subsection{Batch Adsorption Tests}

The adsorbent performance was evaluated in advance by a batch adsorption test. The aqueous solution of 100 ppm Dy (III) and 100 ppm Nd (III) at pH 2 was used as the adsorption solution. After adsorption, the adsorbent was immersed in $1.0 \mathrm{M} \mathrm{HCl}$ solution to completely elute the adsorbed ions and washed with adequate water to conduct the adsorption test again.

The results of the batch adsorption test are shown in Table 3 and Figure 4. In the first adsorption test, all adsorbents had similar Dy (III) adsorptivity around $25.0 \mathrm{mg} / \mathrm{g}$. The EHEP loaded in the fabric is a cationic extractant, which is known to extract metal ions from aqueous solution and can be labeled HA. The adsorption is an ion-exchange process in which one Dy (III) ion combines three EHEPs to form a DyA 3 structure in the adsorbent $[57,58]$. The similar adsorptivity was due to the similar EHEP loading $(1.20 \mathrm{mmol} / \mathrm{g})$ of the four adsorbents. However, the $\mathrm{Nd}$ (III) adsorptivity for each adsorbent was considerably small (less than $1.0 \mathrm{mg} / \mathrm{g}$ ). Therefore, the EHEP-loaded adsorbents had a high adsorption selectivity for Dy (III) and could be used for separation and recovery.

Table 3. Summary of the first and repeated batch adsorption tests.

\begin{tabular}{|c|c|c|c|c|c|c|c|}
\hline \multirow[b]{2}{*}{ Adsorbents } & \multicolumn{3}{|c|}{ 1st Adsorption * } & \multicolumn{3}{|c|}{ Repeated Adsorption ** } & \multirow[b]{2}{*}{$\mathbf{W}_{\mathrm{a}} / \mathbf{W}_{\mathrm{b}}$} \\
\hline & $\begin{array}{c}W_{b} \\
(\mathrm{mg})\end{array}$ & $\begin{array}{c}C_{\text {Dy-1 }} \\
(\mathrm{mg} / \mathrm{g})\end{array}$ & $\begin{array}{c}\mathrm{C}_{\mathrm{Nd}-1} \\
(\mathrm{mg} / \mathrm{g})\end{array}$ & $\begin{array}{c}\mathrm{C}_{\text {Dy-r }} \\
(\mathrm{mg} / \mathrm{g})\end{array}$ & $\begin{array}{c}\mathrm{C}_{\mathrm{Nd}-\mathrm{r}} \\
(\mathrm{mg} / \mathrm{g})\end{array}$ & $\begin{array}{c}W_{\mathrm{a}} \\
(\mathrm{mg})\end{array}$ & \\
\hline BMA & 54 & 28.6 & 0.1 & 11.4 & 0.1 & 40 & 0.74 \\
\hline HMA & 66 & 26.2 & 0.6 & 15.0 & 0.1 & 51 & 0.77 \\
\hline DMA & 80 & 24.9 & 0.4 & 22.7 & 0 & 74 & 0.93 \\
\hline OMA & 86 & 26.0 & 1.0 & 25.3 & 0.8 & 82 & 0.95 \\
\hline
\end{tabular}

* First adsorption was performed using the new adsorbent, and $W_{b}$ is the dry weight of the new adsorbent, $C_{D y-1}$ and $\mathrm{C}_{\mathrm{Nd}-1}$ are the $\mathrm{Dy}(\mathrm{III})$ and $\mathrm{Nd}(\mathrm{III})$ adsorptivities of the first adsorption, respectively; ${ }^{* *}$ Repeated adsorption was performed after the adsorbent diluted and adequate water-washed, $\mathrm{C}_{\mathrm{Dy}-\mathrm{r}}$ and $\mathrm{C}_{\mathrm{Nd}-\mathrm{r}}$ are the Dy(III) and $\mathrm{Nd}(\mathrm{III})$ adsorptivities of the repeated adsorption, respectively, and $\mathrm{W}_{\mathrm{a}}$ is the dry weight of the used adsorbent after the repeated adsorption and dilution. 


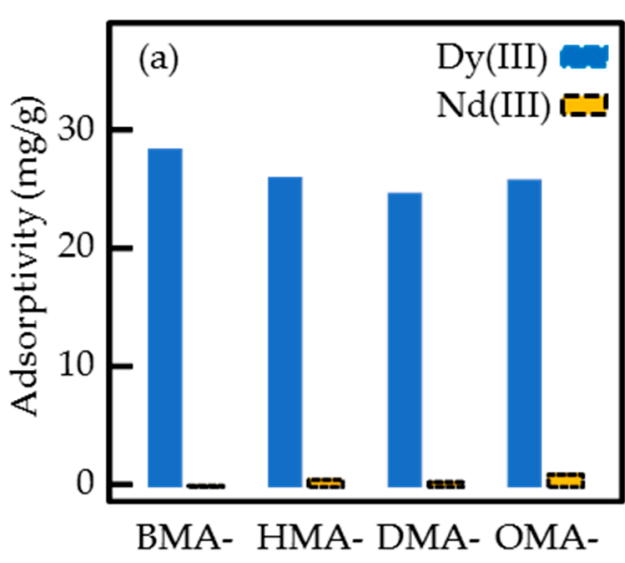

Adsorbents

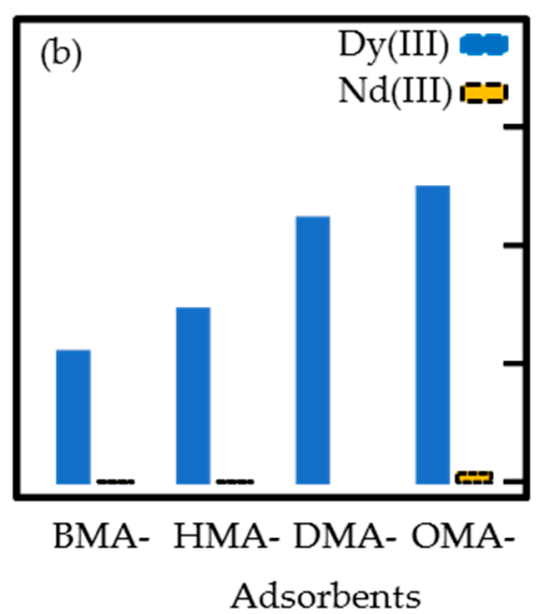

Adsorbents

Figure 4. The Dy (III) and Nd (III) adsorptivity of the four nonwoven fabric adsorbents. (a) First adsorption test. (b) Second adsorption test using the refreshed adsorbents after elution and washing. Initial adsorption solution: $100 \mathrm{ppm}$ Dy (III) and $100 \mathrm{ppm} \mathrm{Nd}$ (III) at a pH of 2.0 at $25^{\circ} \mathrm{C}$.

In the repeated adsorption tests, the OMA-adsorbent retained a high Dy (III) adsorptivity of $25.3 \mathrm{mg} / \mathrm{g}$. In contrast, the Dy (III) adsorptivities of BMA-, HMA-, and DMA-adsorbents were significantly reduced to were $11.4,15.0$, and $22.7 \mathrm{mg} / \mathrm{g}$, respectively. The decrease of Dy (III) adsorptivity might be due to the loss of EHEP loaded in the fabric during the repeated tests. As shown in Table 3, after repeated adsorption tests, the weight of the OMA-adsorbent was almost unchanged, while the weight of the BMA-adsorbent was reduced by $26 \%$. The shorter the alkyl chain length of the grafted monomer, the more the weight of the adsorbent decreased due to the loss of EHEP. According to these results, the OMA-adsorbent with the longest alkyl chain was chosen for the column adsorption test.

\subsection{Column Adsorption Tests}

Column adsorption and elution were carried out using the same adsorption and elution solutions as the above batch tests. The solution was passed through the column at a space velocity of $100 \mathrm{~h}^{-1}$. As shown in Figure 5, the Dy (III) was completely adsorbed up to a higher bed volume (BV) of 80 . After that, the concentration of Dy (III) in the effluent gradually increased, reaching $98 \mathrm{ppm}$ at a BV of 400 (similar to the concentration of the fed solution, $100 \mathrm{ppm}$ ). The total Dy (III) adsorbed from the solution was calculated using Equation (5) to be $43.6 \mathrm{mg} / \mathrm{g}$. The adsorption is an ion-exchange process between the metal ions and the proton of EHEP loaded in the fabrics; that is, one Dy (III) ion can bond with three phosphate groups. Therefore, for a $1.2 \mathrm{mmol} / \mathrm{g}$ EHEP-loaded adsorbent, the calculated adsorption capacity is close to $64.8 \mathrm{mg} / \mathrm{g}$. The detected value of $43.6 \mathrm{mg} / \mathrm{g}$ is lower than the calculated value, which is due to the adsorption equilibria at the low Dy (III) concentration of the feed solution. Even then, it is still much higher than in the case of using hybrid silica nanoparticles, as reported by Topel et al., where the Dy (III) adsorption is $0.019 \mathrm{mmol} / \mathrm{g}$ or $30.9 \mathrm{mg} / \mathrm{g}$ [57]. In contrast, the Nd (III) was completely adsorbed up to a lower BV of 40 , and the $\mathrm{Nd}$ (III) concentration rapidly increased up to $130 \mathrm{ppm}$ at a BV of 144, which was higher than that of the fed solution (100 ppm). This is because the adsorbed Nd (III) was replaced by Dy (III), indicating that the OMA-adsorbent was favorable for Dy (III) adsorption. The Nd (III) adsorptivity of the adsorbents in the column was also calculated using Equation (5) to be $4.2 \mathrm{mg} / \mathrm{g}$, which was one-tenth of the Dy (III) adsorption.

The adsorbed Dy (III) and Nd (III) were eluted by passing $1.0 \mathrm{M} \mathrm{HCl}$ solution through the column. The maximum concentrations of Dy (III) and Nd (III) in the effluent were 373 and 38 ppm, respectively. The recovery ratios of Dy (III) and Nd (III) calculated using Equations (6) and (7) were $99 \%$ and $98 \%$, respectively, indicating that almost all metal ions were eluted by the $1.0 \mathrm{M} \mathrm{HCl}$ solution within a $\mathrm{BV}$ of 160 (from 550 to 710 BV in Figure 5). 
After the first adsorption, water washing, $\mathrm{HCl}$ elution, and water washing, the repeated column test was continued (Figure 5). The concentration curves of Dy (III) and Nd (III) for the repeated adsorption test show similar behavior as the first adsorption test. These results indicate that the OMA-adsorbent was stable for repeated use in the separation and recovery of Dy (III) and Nd (III) ions from an aqueous solution.

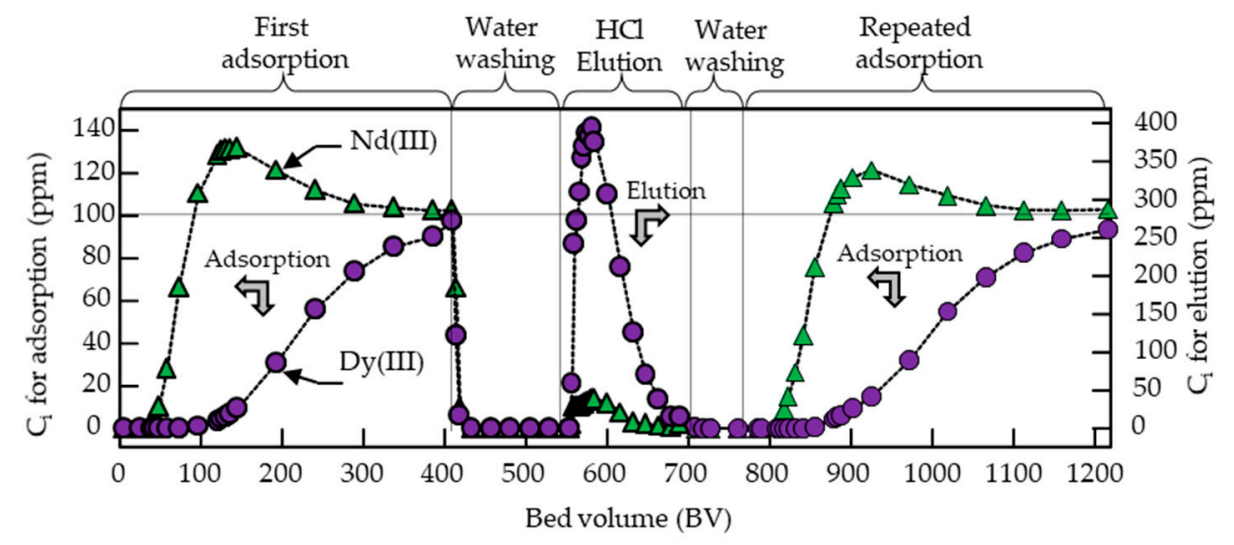

Figure 5. Profile of the adsorption and elution of Dy (III) and Nd (III) ions with an OMA-adsorbent. Adsorption solution: 100 ppm Dy (III) and 100 ppm Nd (III), pH 2.0; elution solution: $1.0 \mathrm{M} \mathrm{HCl}$; space velocity $(\mathrm{SV})=100 \mathrm{~h}^{-1}$; temperature $=25^{\circ} \mathrm{C}$; the total $1200 \mathrm{BV}$ means that the adsorption-elutionadsorption process was operated for $12 \mathrm{~h}$ under the fixed space velocity of $100 \mathrm{~h}^{-1}$.

\section{Conclusions}

A fabric adsorbent for the separation and recovery of Dy (III) and Nd (III) from an aqueous solution was successfully prepared by graft polymerization of methacrylate with a long alkyl chain onto the nonwoven fabric and loading EHEP by hydrophobic interaction and chain entanglement between the alkyl chains.

In the batch adsorption tests, the adsorbents showed a high Dy (III) adsorptivity above $25.0 \mathrm{mg} / \mathrm{g}$ and a low $\mathrm{Nd}$ (III) adsorptivity below $1.0 \mathrm{mg} / \mathrm{g}$, indicating that the adsorbents had a high Dy (III) selective adsorption. However, only the OMA-adsorbent with the longest alkyl chain was stable and retained its high Dy (III) adsorption performance in repeated adsorption tests.

In the column adsorption test with the OMA-adsorbent, the adsorptivities of Dy (III) and Nd (III) were 43.6 and $4.2 \mathrm{mg} / \mathrm{g}$, respectively. The Dy (III) adsorptivity was approximately ten times higher than that of the $\mathrm{Nd}$ (III) adsorptivity. Similar adsorption performance of the adsorbents was observed in the repeated tests. These results demonstrate that the OMA-adsorbent was stable for repeated use. The high stability of the OMA-adsorbents due to the loss of EHEP was suppressed by the strong hydrophobic interaction and chain entanglement between the long alkyl chains.

The OMA-adsorbent can be synthesized easily and economically by immersing the irradiated nonwoven fabric in the monomer solution and EHEP solution in sequence. The obtained adsorbent can be used in batch mode or column mode without any other separation process. Even if the adsorbent is operated in a strong acid, it is stable without any weight loss. Furthermore, the adsorbent has a high selectivity to Dy (III) ions. Therefore, the OMA-adsorbent developed in this study can effectively separate and recover Dy (III) and Nd (III) from an aqueous solution and is expected to contribute to the recovery of rare-earth metals from $\mathrm{NdFeB}$ permanent magnet scraps in the future.

Author Contributions: Conceptualization, H.H. and N.S.; methodology, formal analysis and investigation H.H., J.C. and H.A.; writing—original draft preparation, H.H.; writing—review and editing, J.C.; project administration, N.S.; All authors have read and agreed to the published version of the manuscript.

Funding: This research was partly funded by the Japan Society for the Promotion of Science (JSPS) KAKENHI Grant Numbers JP17K00632 (Grant-in-Aid for Scientific Research (C)).

Conflicts of Interest: The authors declare no conflict of interest. 


\section{References}

1. Schreiber, A.; Marx, J.; Zapp, P.; Hake, J.F.; Voßenkaul, D.; Friedrich, B. Environmental impacts of rare earth mining and separation based on eudialyte: A new European way. Resources 2016, 5, 32. [CrossRef]

2. Akcil, A.; Akhmadiyeva, N.; Abdulvaliyev, R.; Abhilash; Meshram, P. Overview on extraction and separation of rare earth elements from red mud: Focus on scandium. Min. Process. Extr. Metall. Rev. 2018, 39, $145-151$. [CrossRef]

3. Grandell, L.; Lehtilä, A.; Kivinen, M.; Koljonen, T.; Kihlman, S.; Lauri, L.S. Role of critical metals in the future markets of clean energy technologies. Renew. Energy 2016, 95, 53-62. [CrossRef]

4. Golev, A.; Scott, M.; Erskine, P.D.; Ali, S.H.; Ballantyne, G.R. Rare earths supply chains: Current status, constraints and opportunities. Resour. Policy 2014, 41, 52-59. [CrossRef]

5. Dushyantha, N.; Batapola, N.; Ilankoon, I.M.S.K.; Rohitha, S.; Premasiri, R.; Abeysinghe, B.; Ratnayake, N.; Dissanayake, K. The story of rare earth elements (REEs): Occurrences, global distribution, genesis, geology, mineralogy and global production. Ore Geol. Rev. 2020, 122, 103521. [CrossRef]

6. Binnemans, K.; Jones, P.T.; Blanpain, B.; Gerven, T.V.; Yang, Y.; Walton, A.; Buchert, M. Recycling of rare earths: A critical review. J. Clean. Prod. 2013, 51, 1-22. [CrossRef]

7. Machacek, E.; Richter, J.L.; Habib, K.; Klossek, P. Recycling of rare earths from fluorescent lamps: Value analysis of closing-the-loop under demand and supply uncertainties. Resour. Conserv. Recycl. 2015, 104, 76-93. [CrossRef]

8. U.S. Department of Energy. Critical Materials Strategy; U.S. Department of Energy: Washington, DC, USA, 2011; pp. 1-191.

9. Rademaker, J.H.; Kleijn, R.; Yang, Y. Recycling as a strategy against rare earth element criticality: A systemic evaluation of the potential yield of NdFeB magnet recycling. Environ. Sci. Technol. 2013, 47, 10129-10136. [CrossRef]

10. Thakur, N.V.; Jayawant, D.V.; Iyer, N.S.; Koppiker, K.S. Separation of neodymium from lighter rare earths using alkyl phosphonic acid, PC 88A. Hydrometallurgy 1993, 34, 99-108. [CrossRef]

11. Yoon, H.S.; Kim, C.J.; Chung, K.W.; Kim, S.D.; Lee, J.Y.; Kumar, J.R. Solvent extraction, separation and recovery of dysprosium (Dy) and neodymium $(\mathrm{Nd})$ from aqueous solutions: Waste recycling strategies for permanent magnet processing. Hydrometallurgy 2016, 165, 27-43. [CrossRef]

12. Riaño, S.; Binnemans, K. Extraction and separation of neodymium and dysprosium from used $\mathrm{NdFeB}$ magnets: An application of ionic liquids in solvent extraction towards the recycling of magnets. Green Chem. 2015, 17, 2931-2942. [CrossRef]

13. Riaño, S.; Foltova, S.S.; Binnemans, K. Separation of neodymium and dysprosium by solvent extraction using ionic liquids combined with neutral extractants: Batch and mixer-settler experiments. RSC Adv. 2020, 10, 307-316. [CrossRef]

14. Ding, Y.; Harvey, D.; Wang, N.L. Two-zone ligand-assisted displacement chromatography for producing high-purity praseodymium, neodymium, and dysprosium with high yield and high productivity from crude mixtures derived from waste magnets. Green Chem. 2020, 22, 3769-3783. [CrossRef]

15. Alcaraz, L.; Escudero, M.E.; Alguacil, F.J.; Llorente, I.; Urbieta, A.; Fernández, P.; López, F.A. Dysprosium removal from water using active carbons obtained from spent coffee ground. Nanomaterials 2019, 9, 1372. [CrossRef] [PubMed]

16. Gergoric, M.; Ravaux, C.; Steenari, B.M.; Espegren, F.; Retegan, T. Leaching and recovery of rare-earth elements from neodymium magnet waste using organic acids. Metals 2018, 8, 721. [CrossRef]

17. Kim, J.; Azimi, G. Recovery of scandium and neodymium from blast furnace slag using acid baking-water leaching. RSC Adv. 2020, 10, 31936-31946. [CrossRef]

18. Demey, H.; Lapo, B.; Ruiz, M.; Fortuny, A.; Marchand, M.; Sastre, A.M. Neodymium recovery by chitosan/iron (III) hydroxide [ChiFer (III)] sorbent material: Batch and column systems. Polymers 2018, 10, 204. [CrossRef]

19. Matsumiya, M.; Yamada, T.; Kikuchi, Y.; Kawakami, S. Removal of iron and boron by solvent extraction with ionic liquids and recovery of neodymium metal by direct electrodeposition. Solvent Extr. Ion Exch. 2016, 34, 522-534. [CrossRef]

20. Riaño, S.; Petranikova, M.; Onghena, B.; Vander Hoogerstraete, T.; Banerjee, D.; Foreman, M.R.S.; Binnemans, K. Separation of rare earths and other valuable metals from deep-eutectic solvents: A new alternative for the recycling of used NdFeB magnets. RSC Adv. 2017, 7, 32100-32113. [CrossRef] 
21. Zhang, Y.; Gu, F.; Su, Z.; Liu, S.; Anderson, C.; Jiang, T. Hydrometallurgical recovery of rare earth elements from NdFeB permanent magnet scrap: A review. Metals 2020, 10, 841. [CrossRef]

22. Ismail, N.A.; Aziz, M.A.A.; Yunus, M.Y.M.; Hisyam, A. Selection of extractant in rare earth solvent extraction system: A review. Int. J. Recent Technol. Eng. 2019, 8, 728-742.

23. Xie, F.; Zhang, T.A.; Dreisinger, D.; Doyle, F. A critical review on solvent extraction of rare earths from aqueous solutions. Miner. Eng. 2014, 56, 10-28. [CrossRef]

24. Xia, Y.; Xiao, L.; Xiao, C.; Zeng, L. Direct solvent extraction of molybdenum(VI) from sulfuric acid leach solutions using PC-88A. Hydrometallurgy 2015, 158, 114-118. [CrossRef]

25. Zhang, F.; Dai, J.; Wang, A.; Wu, W. Investigation of the synergistic extraction behavior between cerium (III) and two acidic organophosphorus extractants using FT-IR, NMR and mass spectrometry. Inorg. Chim. Acta 2017, 466, 333-342. [CrossRef]

26. Tasaki-Handa, Y.; Abe, Y.; Ooi, K.; Narita, H.; Tanaka, M.; Wakisaka, A. Selective crystallization of phosphoester coordination polymer for the separation of neodymium and dysprosium: A thermodynamic approach. J. Phys. Chem. B 2016, 120, 12730-12735. [CrossRef] [PubMed]

27. Bogart, J.A.; Lippincott, C.A.; Carroll, P.J.; Schelter, E.J. An operationally simple method for separating the rare-earth elements neodymium and dysprosium. Angew. Chem. Int. Ed. 2015, 54, 8222-8225. [CrossRef] [PubMed]

28. Swain, N.; Mishra, S. A review on the recovery and separation of rare earths and transition metals from secondary resources. J. Clean. Prod. 2019, 220, 884-898. [CrossRef]

29. Dong, Z.; Liu, J.; Yuan, W.; Yi, Y.; Zhao, L. Recovery of Au (III) by radiation synthesized aminomethyl pyridine functionalized adsorbents based on cellulose. Chem. Eng. J. 2016, 283, 504-513. [CrossRef]

30. Hayashi, N.; Chen, J.; Seko, N. Nitrogen-containing fabric adsorbents prepared by radiation grafting for removal of chromium from wastewater. Polymers 2018, 10, 744. [CrossRef]

31. Abney, C.W.; Mayes, R.T.; Saito, T.; Dai, S. Materials for the recovery of uranium from seawater. Chem. Rev. 2017, 117, 13935-14013. [CrossRef]

32. Liu, S.; Xu, M.; Yu, T.; Han, D.; Peng, J.; Li, J.; Zhai, M. Radiation synthesis and performance of novel cellulose-based microsphere adsorbents for efficient removal of boron (III). Carbohyd. Polym. 2017, 174, $273-281$. [CrossRef] [PubMed]

33. Chi, F.; Zhang, S.; Wen, J.; Xiong, J.; Hu, S. Functional polymer brushes for highly efficient extraction of uranium from seawater. J. Mater. Sci. 2019, 54, 3572-3585. [CrossRef]

34. Li, R.; Li, Y.; Zhang, M.; Xing, Z.; Ma, H.; Wu, G. Phosphate-based ultrahigh molecular weight polyethylene fibers for efficient removal of uranium from carbonate solution containing fluoride ions. Molecules 2018, 23, 1245. [CrossRef]

35. Tran, T.H.; Okabe, H.; Hidaka, Y.; Hara, K. Removal of metal ions from aqueous solutions using carboxymethyl cellulose/sodium styrene sulfonate gels prepared by radiation grafting. Carbohyd. Polym. 2017, 157, 335-343. [CrossRef]

36. Li, C.; Zhang, Y.; Peng, J.; Wu, H.; Li, J.; Zhai, M. Adsorption of Cr (VI) using cellulose microsphere-based adsorbent prepared by radiation-induced grafting. Radiat. Phys. Chem. 2012, 81, 967-970. [CrossRef]

37. Ray, P.Z.; Shipley, H.J. Inorganic nano-adsorbents for the removal of heavy metals and arsenic: A review. RSC Adv. 2015, 5, 29885-29907. [CrossRef]

38. Topel, S.D.; Legaria, E.P.; Tiseanu, C.; Rocha, J.; Nedelec, J.M.; Kessler, V.G.; Seisenbaeva, G.A. Hybrid silica nanoparticles for sequestration and luminescence detection of trivalent rare-earth ions $\left(\mathrm{Dy}^{+}\right.$and $\mathrm{Nd}^{+}$) in solution. J. Nanopart. Res. 2014, 16, 2783. [CrossRef]

39. Gu, S.; Kang, X.; Wang, L.; Lichtfouse, E.; Wang, C. Clay mineral adsorbents for heavy metal removal from wastewater: A review. Environ. Chem. Lett. 2019, 17, 629-654. [CrossRef]

40. Nasef, M.M.; Gürsel, S.A.; Karabelli, D.; Güven, O. Radiation-grafted materials for energy conversion and energy storage applications. Progr. Polym. Sci. 2016, 63, 1-41. [CrossRef]

41. Zhilyaeva, N.A.; Lytkina, A.A.; Mironova, E.Y.; Ermilova, M.M.; Orekhova, N.V.; Shevlyakova, N.V.; Tverskoy, V.A.; Yaroslavtsev, A.B. Polyethylene with radiation-grafted sulfonated polystyrene membranes for butane and butenes separation. Chem. Eng. Res. Des. 2020, 161, 253-259. [CrossRef]

42. Sherazi, T.A.; Guiver, M.D.; Kingston, D.; Ahmad, S.; Kashmiri, M.A.; Xue, X. Radiation-grafted membranes based on polyethylene for direct methanol fuel cells. J. Power Sour. 2010, 195, 21-29. [CrossRef] 
43. Mandal, D.V.; Bhunia, H.; Bajpai, P.K.; Bhalla, V.K. Thermal degradation kinetics and estimation of lifetime of radiation grafted polypropylene films. Radiat. Phys. Chem. 2017, 136, 1-8. [CrossRef]

44. Bondar, Y.; Kim, H.J.; Yoon, S.H.; Lim, Y.J. Synthesis of cation-exchange adsorbent for anchoring metal ions by modification of poly (glycidyl methacrylate) chains grafted onto polypropylene fabric. React. Funct. Polym. 2004, 58, 43-51. [CrossRef]

45. Chen, J.; Seko, N. Cleavage of the graft bonds in PVDF-g-St films by boiling xylene extraction and the determination of the molecular weight of the graft chains. Polymers 2019, 11, 1098. [CrossRef] [PubMed]

46. Seko, N.; Basuki, F.; Tamada, M.; Yosaii, F. Rapid removal of arsenic(V) by zirconium(IV) loaded phosphoric chelate adsorbent synthesized by radiation induced graft polymerization. React. Funtc. Polym. 2004, 59, $235-241$. [CrossRef]

47. Ha, H.; Wu, L.; Tai, H.; Zhang, Z.; Wei, J.; Wu, J. Study of radiation grafting of styrene on cotton cellulose. Radiat. Phys. Chem. 1995, 46, 823-827.

48. Gad, H.M.H.; Hamed, M.M.; Eldahab, H.A.; Moustafa, M.E.; El-Reefy, S.A. Radiation-induced grafting copolymerization of resin onto the surface of silica extracted from rice husk ash for adsorption of gadolinium. J. Mol. Liq. 2017, 231, 45-55. [CrossRef]

49. Ueki, Y.; Seko, N. Synthesis of Fibrous metal adsorbent with a piperazinyl-Dithiocarbamate group by radiation-induced grafting and its performance. ACS OMEGA 2020, 5, 2947-2956. [CrossRef]

50. Shibata, T.; Seko, N.; Amada, H.; Kasai, N.; Saiki, S.; Hoshina, H.; Ueki, Y. Evaluation of a cesium adsorbent grafted with ammonium 12-molybdophosphate. Radiat. Phys. Chem. 2016, 119, 247-252. [CrossRef]

51. Othman, N.A.F.; Selambakkannu, S.; Yamanobe, T.; Hoshina, H.; Seko, N.; Abdullah, T.A.T. Radiation grafting of DMAEMA and DEAEMA-based adsorbents for thorium adsorption. J. Radioanal. Nucl. Chem. 2020, 324, 429-440. [CrossRef]

52. Zhang, W.; Avdibegović, D.; Koivula, R.; Hatanpää, T.; Hietala, S.; Regadío, M.; Harjula, R. Titanium alkylphosphate functionalised mesoporous silica for enhanced uptake of rare-earth ions. J. Mater. Chem. A 2017, 5, 23805-23814. [CrossRef]

53. Ueki, Y.; Saiki, S.; Hoshina, H.; Seko, N. Biodiesel fuel production from waste cooking oil using radiation-grafted fibrous catalysts. Radiat. Phys. Chem. 2018, 143, 41-46. [CrossRef]

54. Fonseca, J.L.C.; Apperley, D.C.; Plasma, J.P.S. Plasma polymerization of tetramethylsilane. Chem. Mater. 1993, 5, 1676-1682. [CrossRef]

55. Nava-Ortiz, C.A.B.; Burillo, G.; Bucio, E.; Alvarez-Lorenzo, C. Modification of polyethylene films by radiation grafting of glycidyl methacrylate and immobilization of $\beta$-cyclodextrin. Radiat. Phys. Chem. 2009, 78, $19-24$. [CrossRef]

56. Ormond-Prout, J.; Dupin, D.; Armes, S.P.; Foster, N.J.; Burchell, M.J. Synthesis and characterization of polypyrrole-coated poly (methyl methacrylate) latex particles. J. Mater. Chem. 2009, 19, 1433-1442. [CrossRef]

57. Yin, S.H.; Li, S.W.; Xie, F.; Zhang, L.B.; Peng, J.H. Study on the aqueous solution behavior and extraction mechanism of $\mathrm{Nd}$ (III) in the presence of the complexing agent lactic acid with di-(2-ethylhexyl) phosphoric acid. RSC Adv. 2015, 5, 64550-64556. [CrossRef]

58. Pathak, S.K.; Tripathi, S.C.; Singh, K.K.; Mahtele, A.K.; Dwivedi, C.; Juby, K.A.; Bajaj, P.N. PC-88A-impregnated polymeric beads: Preparation, characterization and application for extraction of $\mathrm{Pu}(\mathrm{IV})$ from nitric acid medium. Radiochim. Acta 2013, 101, 761-771. [CrossRef]

Publisher's Note: MDPI stays neutral with regard to jurisdictional claims in published maps and institutional affiliations.

(C) 2020 by the authors. Licensee MDPI, Basel, Switzerland. This article is an open access article distributed under the terms and conditions of the Creative Commons Attribution (CC BY) license (http://creativecommons.org/licenses/by/4.0/). 